\title{
The role of intangible assets in the conservation of Bam and its cultural landscape as a World Heritage site
}

\author{
G. Amirjamshidi ${ }^{1}$, E. Fodde ${ }^{1}$, D. D’Ayala ${ }^{1}$ \& E. Mokhtari ${ }^{2}$ \\ ${ }^{1}$ Department of Architecture and Civil Engineering, \\ University of Bath, UK \\ ${ }^{2}$ Faculty of Art and Architecture, Azad University, Tehran, Iran
}

\begin{abstract}
Buildings must pass the test of authenticity and integrity to be considered as World Heritage sites. The combination of these attributes can be referred to as the genuineness of the site.

Bam suffered from a devastating earthquake in December 2003, but even after the disaster, the area was acknowledged to have a high degree of authenticity and integrity and was successfully put forward for consideration as a World Heritage site. Apart from the uniqueness of Bam's Citadel as the world's greatest mud brick structure and of a number of buildings in the immediate vicinity of the Citadel, the rationale for its inscription was also influenced by its intangible aspects and cultural landscape. Examples of intangible heritage in Bam include the legend of Haftvad and the Kot-e Kerm and its relation to the Silk Road as well as the beliefs of people of Bam in the rituals linked to the well of the Master of Time (Imam Zaman), and the ritual of Ashura.

Until recently, the integrity of a World Heritage site was mostly assessed by studying its tangible heritage. However, in 1982, UNESCO introduced a new mandate for consideration of intangible heritage to emphasise its significance and to strive for protection of traditional culture and folklore. Several regional assessments have since been made on the impacts and recommendations on the protection of traditions, culture and folklore. When protecting a tangible heritage site, the practice is mainly based on pragmatic conservation and restoration.
\end{abstract}


Non-tangible heritage, on the other hand, is more subtle and requires more sophisticated approaches and methods for its preservation.

This paper investigates the intangible heritage associated with the Bam Citadel as part of Bam and its cultural landscape and, where appropriate, highlights the relationship between these assets and the architectural aspects to accentuate the cultural importance of this of World Heritage site.

\section{The role of authenticity and integrity in World Heritage conservation}

The operational guideline for the implementation of the World Heritage Convention (2008) [1] argues that the properties nominated as Cultural Heritage must meet the prerequisite of authenticity.

The Citadel of Bam is a unique architectural site; it is not only one of the world's biggest mud-brick structures, but it also gains uniqueness and authenticity from its intangible heritage.

During the past decade, new approaches have been developed with the aim of including intangible heritage as a source of cultural identity, creativity and diversity. In the Washington International Conference in 1999 [2], it was mentioned that there is a need to emphasise on traditional-bearers rather than scholars. The importance of considering not only the artistic aspects, such as tales and folklores, but also the knowledge and values that enabled their production was also mentioned. The underlying notion was to draw attention to the fact that it was because of the existence of beliefs and people's modes of interaction that these Heritage came to exist.

The Nara Document on Authenticity [3] also challenges different attitudes towards the conservation of World Heritage sites and strives to give more respect to cultural and heritage diversity in the field. According to the charter, the physical heritage should be considered within the cultural context and value and authenticity of architectural cultural heritage cannot be based on fixed criteria.

Consequently, the "Yamato Declaration on Integrated Approaches for Safeguarding Tangible and Intangible Cultural Heritage" was established in 2004. The aim of this declaration was to stimulate worldwide argument on possible approaches towards the safeguarding of tangible and intangible cultural heritage [4].

In conservation of World Heritage sites, values such as character-defining features, integrity and authenticity should be given special attention; these values are the essence around which the site was originally built.

\section{The citadel of Bam}

The Iranian government used the guidelines established in the 2003 UNESCO Convention for the Safeguarding of Intangible Heritage for preserving the intangible values of Bam and its cultural landscape as a World Heritage. Number 
of values are substantial in conservation of Bam and its cultural landscape, but only the values related to the citadel of Bam will be defined in this paper. These values can be characterised as tradition, ceremony, art, events and legends, food, clothing and craftsmanship.

In the case of Bam, the following categories should be considered: the legends, the arts, the culture and the religious rituals.

The Citadel is divided into two parts: the government area and the residential area. In both parts, the residents built high status monuments as well as simpler buildings based on their ethical values, social costumes, beliefs and myths.

The buildings considered in this paper are the main watchtower and the Kot-e Kerm Gate which are located in the government area and the main mosque, the "Master of Time Well", the Mirza Naeem school, the Tekieh, Peyambar Mosque and Zoorkhaneh which are in the residential part of the city.

\subsection{The legends}

There are number of myths and legends about the city of Bam. The oldest and most popular story is the legend of Haftvad and Kot-e Kerm. Some believe that Bam is a short form of Bahman, the name of a mythical king of Persia; others relate Bam to the famous story of Haft Baad in the Book of Kings by Ferdowsi et al. [5], the 10 th century Iranian poet. This story is about a family who had seven sons and one daughter. One day, the daughter finds a worm in an apple. The girl takes care of the worm and as time goes by, the worm grows into a powerful dragon and brings power and prosperity to that family [6]. It is quite likely that the Kot-e-Kerm gate (Figure 1) is named after this worm.

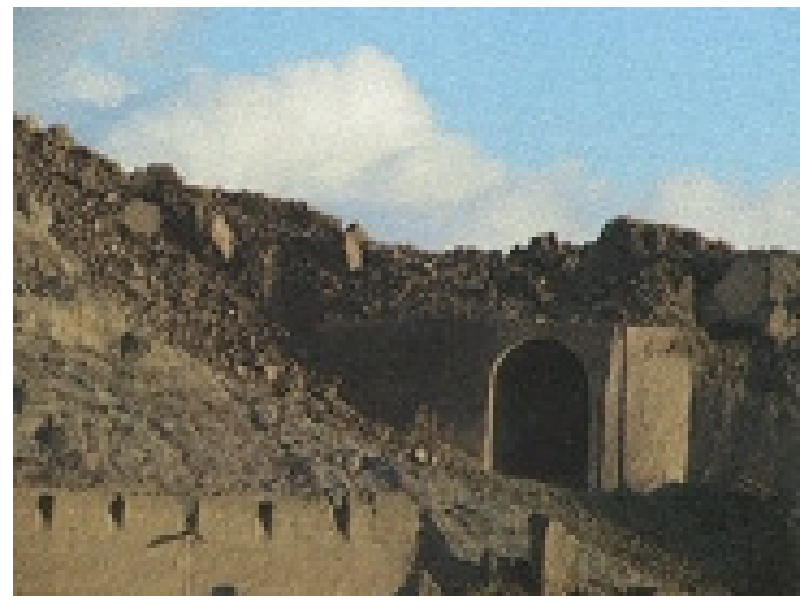

Figure 1: The Kot-e-Kerm gate after the earthquake [7]. 


\subsection{The arts}

Bam is the birthplace of the Dohol, a percussive musical instrument [8], that is principally used locally. Figure 2 shows the Dohol being used in the sacred ceremony of Ashura. (Ashura is an important day for the Shia Muslims all over the world and is on the tenth of Muharram in the Islamic calendar and is a day for Shia muslims to mourn for their third Imam who died in the battle of Karbala. Iranians consider Ashura as the holiest martyr day of the year.)

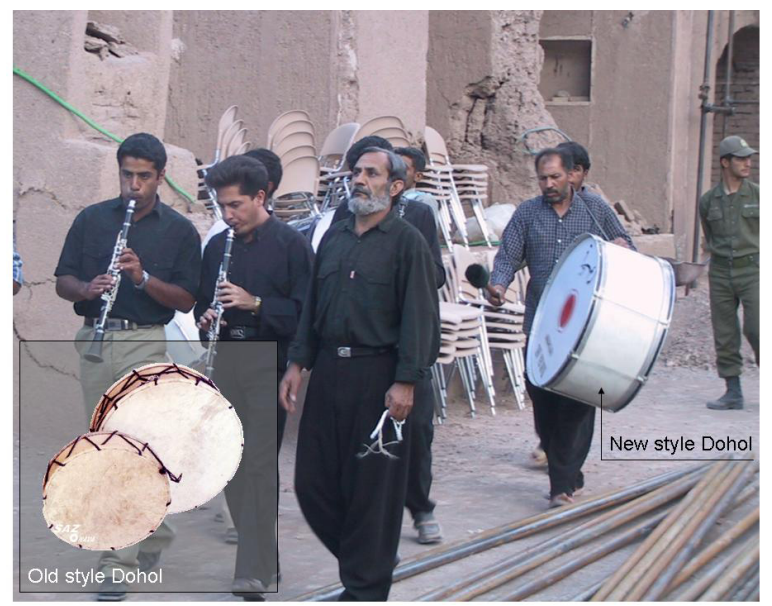

Figure 2: Old style Dohol [9] and a modern rendition being played in Ashura [10].

A quite different aspect of the artistic heritage in Bam can be seen in the Zoorkhaneh [11]. Zoorkhaneh literally means "The house of strength" and is the old Iranian traditional gymnasium. In ancient Iran, group exercise was performed as a sacred ceremony in the Zoorkhaneh. These ceremonies were similar to ritualistic group dances where the Morshed (mentor) played the drums with a rhythm for the athletes to adjust their moves. The Zoorkhaneh of the Citadel is located in north-east of the Mirza Naeem complex.

\subsection{The culture}

Since ancient times, Bam has not only been a trade centre, but also an agricultural centre. What made Bam different from its neighbouring cities, was the availability of water sources. The availability of water in Bam is due to a combination of geological, morphological, existence of Bam Fault and an artificial system of water supply called "Qanat". This ancient method of delivering groundwater to lower areas without evaporation is typical of hot arid areas. It can be found in several countries stretching from Spain to China and is also known as Foggara (North Africa) and Qanat or Kareez (Middle East). These underground tunnels are 


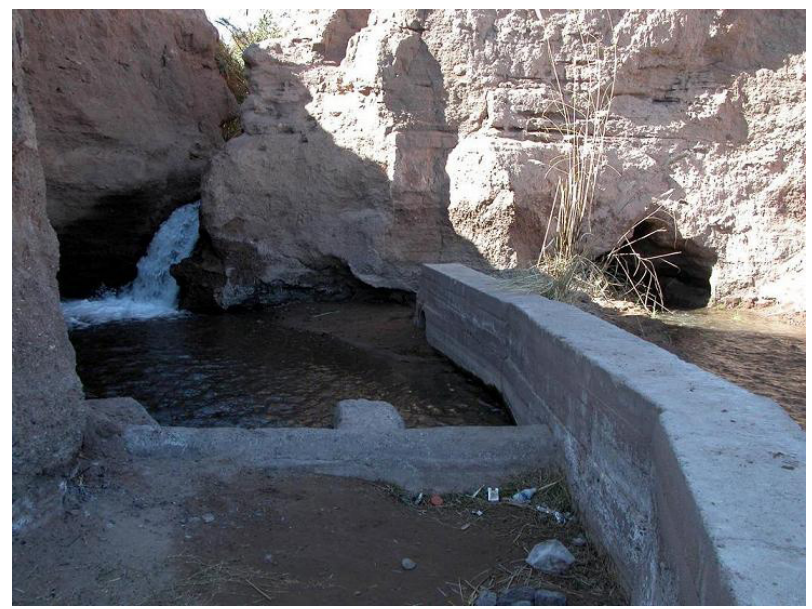

Figure 3: A view of a Qanat near the Bam Citadel [13].

man-made and the specialised workforce constructing the Qanats were known as "Muqannis" [12]. Figure 3 shows a Qanat near the city of Bam.

The Qanat culture is comparable to part of The Cultural Space of the Bedu in Petra and Wadi Rum which was inscribed on the Intangible Cultural Heritage of Humanity list in 2008 [14]. Being located in an arid climate, one of these cultures was Nabatean water-collecting system from near Petra. The Bedu tribes still use this skill for collecting water.

\subsection{The religious rituals}

Religion has always been an important factor in the life of Iranian people [15]. Due to the considerable leading role of religion before and after Islam, religious places such as temples, mosques and Imamzadehs (tombs of descendants of the Shia Imams; often developed as holy shrines where pilgrims seek divine intervention to solve their problems in exchange for offerings) are known to be sacred and command great respect from the Iranian people.

\subsubsection{The main watchtower}

The main watchtower in the government area was the highest point in the skyline of the citadel and its rituals go back to the pre-Islamic era. This tower was constructed in the site of the "Four Season" building (Chahar Fasl). (It is said that the Four Season building was constructed according to the Zoroastrians' beliefs and was originally a fire temple. Fire temples are Zoroastrian's sacred places of worship comparable to Churches for Christians and Mosques for Muslims.) The Watchtower was where the "Sacred fire" was kept and hence it was known as the "Fire tower". It is also said that the fire also helped the travellers braving the 

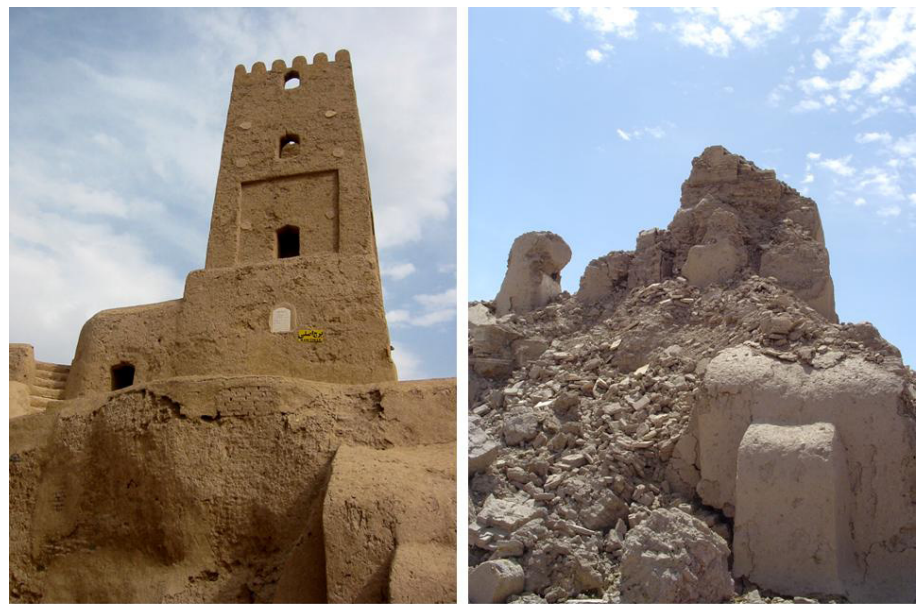

Figure 4: The main Watchtower before and after the earthquake [9].

surrounding desert to find their way. Figure 4 shows the tower before and after the earthquake.

\subsubsection{The Jameh Mosque}

The main mosque (Jameh Mosque) in the Citadel was built in the 8th century and is one of the oldest mosques in Iran. The legends related to the mosque mention that it was built on the site that was previously a Zoroastrian fire temple [7]. It is also said that ancient Iranians that were known to be the builders of the Citadel worshiped fire. Therefore, they made a big fire wherever they wanted to start a civilisation. The place they made the fire was then called "Atashkadeh". After Islam, this mosque replaced this building and was frequented by the local people who have strong religious beliefs. After the earthquake, the mosque was completely destroyed; leaving the local population without their place of worship and a strong community hub. Figure 5 shows the main mosque before and after the earthquake.

\subsubsection{The "Master of time" well}

The majority of the population in Bam are Twelver Shias who believe in 12 Imams. According to the Twelver's beliefs, the twelfth Imam, "Imam Mahdi" (also known as the Master of Time), has been living in The Occultation since 872 CE [16]. Popular legends offer many likely places where this messianic figure will return to bring justice to the world. One such legend points to the "Master of time" well in Bam. This well is near the main mosque and has very important ritual significance to the people of Bam. They believe that by throwing coins inside the well, they can talk and ask for help from the last Imam. 

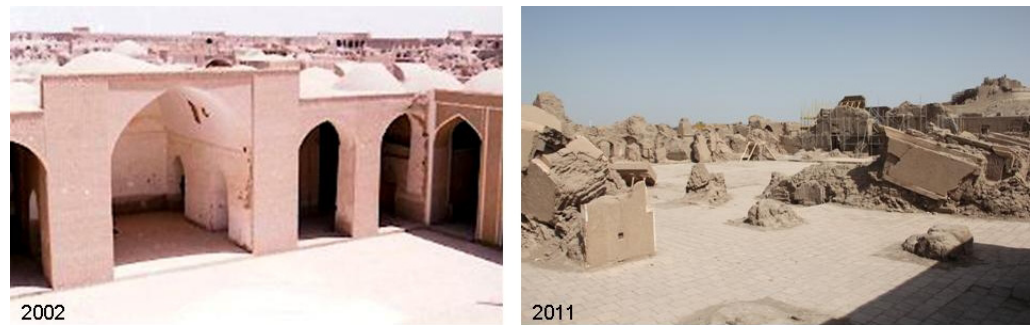

Figure 5: The Jameh Mousque in 2002 [9] and 2011 (by the author).

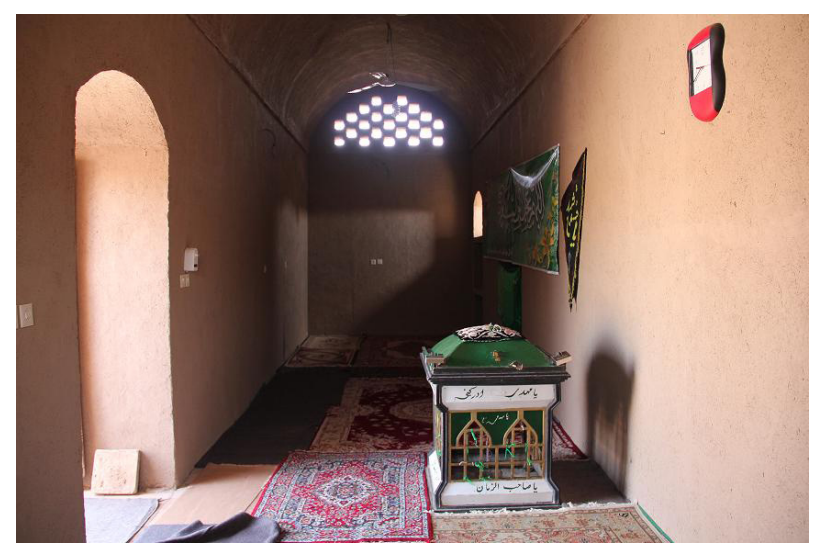

Figure 6: The "Master of Time Well”, 2011 (by the author 2011).

\subsubsection{Mirza Naeem school}

The Mirza Naeem school, a religious Madrasa, is a part of the Mirza Naeem complex which is located to the north of the main mosque. It is said that this complex was built in the 18th century and previous to that, the school used to be a Khangah (Khangah or Khanigah is a building used by the Sufi for worship and spiritual retreat).

\subsubsection{The Tekiyyeh}

The Tekiyyeh or the Religious Theatre is located to the north-east of the Bazar in the citadel. It was an open courtyard for the ceremony of Ta'zieh to take place. The Ta'zieh is a group play conducted to spiritually participate in grieving for the 3rd Imam of Shia and the 72 innocents that were killed in the year $61 \mathrm{AH}$ (Hijri calendar or Islamic calendar) $(680 \mathrm{CE})$ in the battle of Karbala [17]. In this ceremony, people pass through the streets carrying the elements of the drama. The Ta'zieh usually takes place around Ashura. In the Safavid period, people went to the second and third stories of the open courtyard to watch the event [8]. Figure 7 shows the day of Ashura in Bam in 2007. 


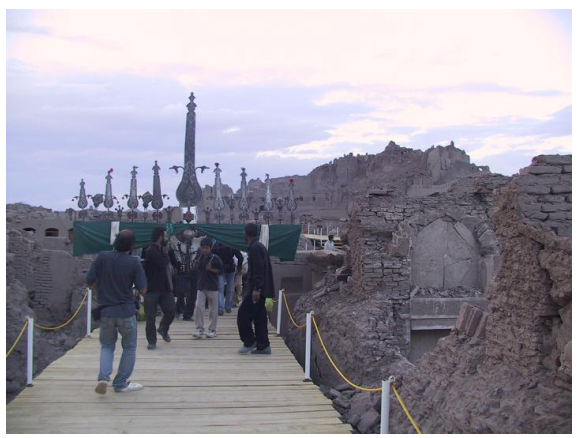

Figure 7: Ashura in Bam Citadel after the earthquake [9].

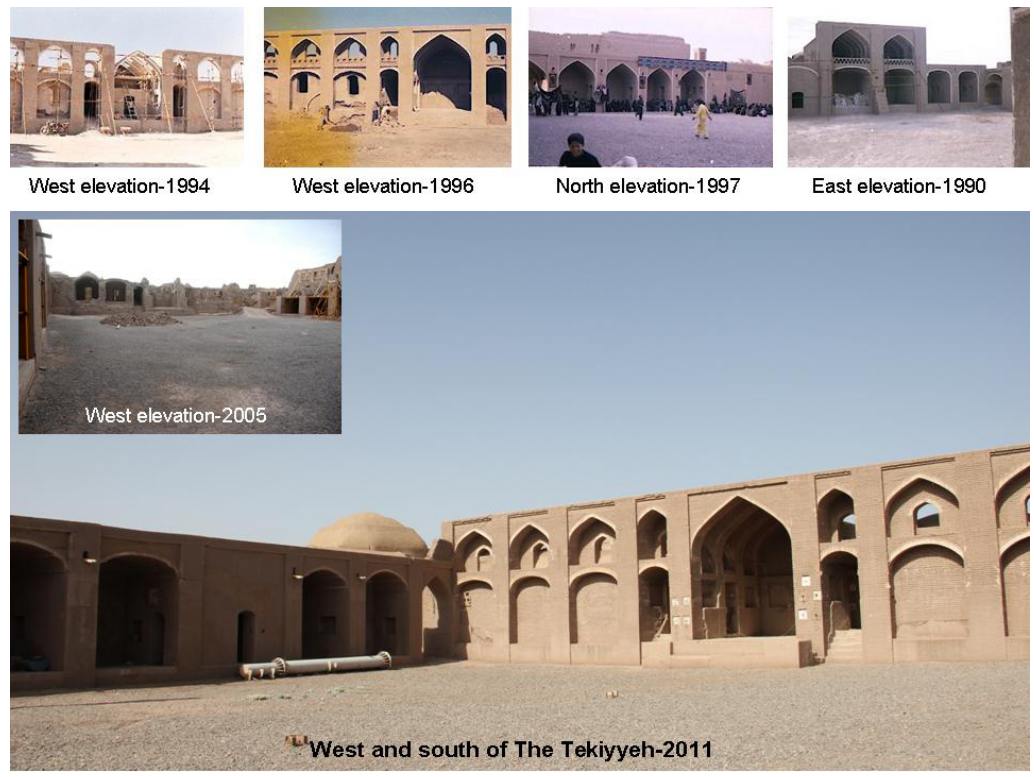

Figure 8: The Tekieh through time [9] (the picture of 2011 is by the author).

The Tekiyyeh was fully restored before the earthquake of 2003 but was extensively destroyed in the earthquake (Figure 8).

\subsubsection{The Peyambar Mosque}

The Peyambar Mosque is located to the north-west of the Bazar. This building was the local mosque and smaller than the main mosque that is located in the citadel. The Payambar mosque was fully destroyed during the 2003 earthquake. In 2011 it was completely rebuilt (Figure 9). 

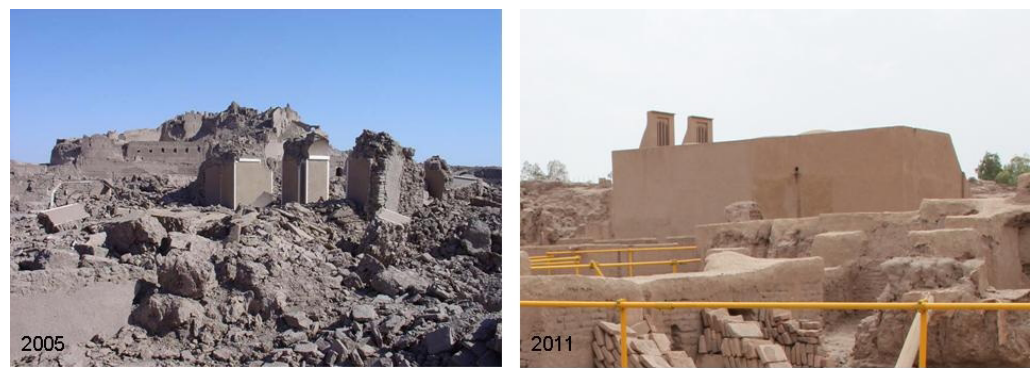

Figure 9: The Payambar mosque in 2005 [9] and 2011(photograph by the author).

\section{Conclusion}

The Citadel of Bam is characterised by many buildings that are associated to legends or oral history and this should be considered when updating the conservation plan. The Tombs of Buganda Kings at Kasubi (Uganda) [18], the historic cities of the Straits of Malacca (Malaysia) [19] and the Armenian Monastic Ensembles of Azarbayjan (Iran) [20] are World Heritage listed buildings with similar intangible assets and these are an integral part of their authenticity.

In this paper, the rich set of intangible assets in Bam were identified and categorised. The legends, the culture, the arts and the religious rituals are essential parts of the authenticity of Bam and its cultural heritage. These aspects are what remains of the original intellectual and cultural landscape which gave rise to the architectural wonder that is the Bam citadel and without them the value and significance of the monument suffers a great loss.

It is, therefore, of the utmost importance for future management plans and conservation plans to consider these aspects as essential parts of what needs to be preserved for future generations. Only by doing so, the authenticity and the integrity of the monument can be maintained whilst plans that neglect these aspects will result in the loss of genuineness in Bam.

\section{References}

[1] WHC, Operational guidelines for the implementation of the world heritage convention, 2008.

[2] Bouchenaki, M., The interdependency of the tangible and intangible cultural heritage, 2003.

[3] ICOMOS, International Charters for the Conservation and Restoration, Monuments and sites. ICOMOS, 2nd edition, pp. 118-121, 2004.

[4] ICOMOS, Yamato declaration on integrated approaches for safeguarding tangible and intangible cultural heritage, 2004. International Conference on The Safeguarding of Tangible and Intangible Heritage Organized by the Japanese Agency for Cultural Affairs and UNESCO. 
[5] Ferdowsi, A., Davis, D. \& Nafisi, A., Shahnameh: the Persian book of kings. Penguin Classics, 2007.

[6] Mahalati, M., The History of Iranian Architecture and Urbanism. Iranian Cultural Heritage Organization, 1999. In Persian.

[7] Jafarizadeh, M., Religious and sacramental aspects in arg-e bam complex. Annual Report of Arg-e-Bam Research Foundation, 1(1), pp. 137-149, 2005. In Persian.

[8] ICHHTO, U.J., UNESCO Tehran, Bam \& its cultural landscape world heritage property, comprehensive management plan 2008-2017, 2008.

[9] RPBCH, RPBCH Archive, 2011.

[10] Drums, P., Persian drums, instruments. http://www.persiandrums.com/home/instruments.htm, 2007. Accessed on $20 / 06 / 2011$.

[11] Amirtash, A., Zoorkhaneh and varzesh-e-bastani. Journal of Movement Science, 5(1), pp. 59-73, 2008.

[12] Beaumont, P., Qanat systems in iran. Bulletin of the International Association of Scientific Hydrology, 16(1), pp. 39-50, 1971.

[13] Adl, S., Qanats of bam, an archaeological survey, 2005. National Workshop on Qanats of Bam, Bam - Iran, UNESCO Tehran Office.

[14] UNESCO, The cultural space of the Bedu in Petra and wadi rum. http://www.unesco.org/culture/, 2008. Accessed on 20/06/2011.

[15] Brookshaw, D., Religion in iran, 2002.

[16] Al-Tabătabă'i, M. \& Nasr, S., Shi 'ite Islam. State University of New York Press, 1975.

[17] Britannica, E., Encyclopædia britannica online, 2008.

[18] WHS Nomination Document, The Tombs of Buganda Kings at Kasubi (Uganda), 2001.

[19] WHS Nomination Document, The Historic Cities of the Straits of Malacca (Malaysia), 2007.

[20] CHHTO Iran, WHS Nomination Document, The Armenian Monastic Ensembles in Iranian Azarbayjan, 2007. 